\title{
Genome-wide profiling of DNA 5-hydroxymethylcytosine during rat Sertoli cell maturation
}

\author{
Miriam Landfors ${ }^{1}$, Jostein Johansen², Jan Magnus Aronsen ${ }^{3,4}$, Cathrine Broberg Vågbø $\varnothing^{2}$, Louis C Doré \\ Chuan $\mathrm{He}^{5}$, Ivar Sjaastad ${ }^{3}$, Pål Sætrom, ${ }^{2,6}$, Péter Fedorcsák ${ }^{7}$, John Arne Dahl ${ }^{1}$, Håvard Aanes ${ }^{1}$, \\ Markus Fußer ${ }^{1,8}$, Arne Klungland ${ }^{1,9, *}$ \\ ${ }^{1}$ Department of Microbiology, Institute of Medical Microbiology, Rikshospitalet, Oslo University Hospital, Oslo, Norway; \\ ${ }^{2}$ Department of Cancer Research and Molecular Medicine, NTNU_Norwegian University of Science and Technology, \\ Trondheim, Norway; ${ }^{3}$ Institute for Experimental Medical Research, Oslo University Hospital and University of Oslo, Oslo, \\ Norway; ${ }^{4}$ Bjørknes College, Oslo, Norway; ${ }^{5}$ Department of Chemistry, Institute for Biophysical Dynamics, Howard Hughes \\ Medical Institute, The University of Chicago, Chicago, IL, USA; ${ }^{6}$ Department of Computer and Information Science, \\ NTNU_Norwegian University of Science and Technology, Trondheim, Norway; ${ }^{7}$ Department of Reproductive Medicine, Oslo \\ University Hospital, Oslo, Norway; ${ }^{8}$ Department of Tumor Biology, Institute for Cancer Research, Oslo University Hospital, \\ Oslo, Norway; ${ }^{9}$ Department of Molecular Medicine, Institute of Basic Medical Sciences, University of Oslo, Oslo, Norway
}

Sertoli cells have dual roles during the cells' lifetime. In the juvenile mammal, Sertoli cells proliferate and create the structure of the testis, and during puberty they cease to proliferate and take on the adult role of supporting germ cells through spermatogenesis. Accordingly, many genes expressed in Sertoli cells during testis formation are repressed during spermatogenesis. 5-Hydroxymethylcytosine $(5 \mathrm{hmC})$ is a DNA modification enzymatically generated from $5 \mathrm{mC}$ and present in all investigated mammalian tissues at varying levels. Using mass spectrometry and immunofluorescence staining we identified a substantial Sertoli cell-specific global $5 \mathrm{hmC}$ increase during rat puberty. Chemical labeling, pull-down and sequencing of $5 \mathrm{hmC}$-containing genomic DNA from juvenile and adult rat Sertoli cells revealed that genes that lose or gain $5 \mathrm{hmC}$ belong to different functional pathways and mirror the functions of the cells in the two different states. Loss of $5 \mathrm{hmC}$ is associated with genes involved in development and cell structure, whereas gain of $5 \mathrm{hmC}$ is associated with genes involved in cellular pathways pertaining to the function of the adult Sertoli cells. This redistribution during maturation shows that $5 \mathrm{hmC}$ is a dynamic nucleotide modification, correlated to gene expression.

Keywords: 5-hydroxymethylcytosine; epigenetics; DNA modification; Sertoli cells; cellular maturation Cell Discovery (2017) 3, 170013; doi:10.1038/celldisc.2017.13; published online 9 May 2017

\section{Introduction}

There are $\sim 200$ different cell types in the body of a mammal. Cellular identity is linked to and maintained by a unique epigenetic make-up. During differentiation, cells acquire epigenetic barriers that prevent cells from transitioning into a less or more differentiated state [1].

5-hydroxymethylcytosine $(5 \mathrm{hmC})$ was identified in 2009 as a frequent modification of mammalian

*Correspondence: Arne Klungland

Tel: +47-2-47840305; Fax: +47 23074061

E-mail: arne.klungland@medisin.uio.no

Received 12 December 2016; accepted 24 February 2017 genomic DNA, and was reported to be particularly enriched in the brain [2]. The ten-eleven translocation (TET) enzymes, belonging to the $\mathrm{Fe}(\mathrm{II})$ and 2-oxoglutarate-dependent TET family, were found to oxidize $5 \mathrm{mC}$ to $5 \mathrm{hmC}$ in mouse [3, 4]. $5 \mathrm{hmC}$ is present in all mammalian tissues investigated to date [5], and its global levels differ significantly among tissues and cell types [6]. Indeed, the tissue type is the main determinant for the $5 \mathrm{hmC}$ level of any given gene [6]. Cell states also seem to exhibit differences in $5 \mathrm{hmC}$ levels: in embryonic stem cells, global $5 \mathrm{hmC}$ content decreases during differentiation [7], whereas tissuespecific neuronal cells acquire $5 \mathrm{hmC}$ upon differentiation [8]. Furthermore, conserved features of the $5 \mathrm{hmC}$ 
distribution in the genome have emerged: $5 \mathrm{hmC}$ is enriched in gene bodies and depleted in intergenic regions $[8,9]$. In addition to its role as epigenetic mark, it has been suggested that the oxidation of $5 \mathrm{mC}$ to $5 \mathrm{hmC}$ is the first step in a consecutive demethylation pathway that ultimately reintroduces a cytosine. As a part of this demethylation pathway, TET enzymes convert $5 \mathrm{hmC}$ further to 5-formylcytosine and 5-carboxylcytosine, which would serve as substrates for DNA glycosylases of the base excision repair pathway that restores cytosine [10-12]. However, the distribution of $5 \mathrm{hmC}$ has been found to be unique and not simply a consequence of $5 \mathrm{mC}$ distribution [13], with
$5 \mathrm{hmC}$ being more selectively enriched in genes than $5 \mathrm{mC}$ [14]. In addition, while $5 \mathrm{hmC}$ levels vary strongly among different cell types, levels of $5 \mathrm{mC}$ are relatively similar across tissues [5].

Sertoli cells have an important role in the formation and development of the mammalian testis, being the first cells to differentiate in the fetal gonad $[15,16]$. The formation of the basic structures of the testis is followed by rapid proliferation of Sertoli cells [15]. At the time of puberty, Sertoli cells mature, lose the ability to proliferate and take on the role of supporting the developing germ cells with nutrients and regulatory factors [16]. The supporting functions of adult
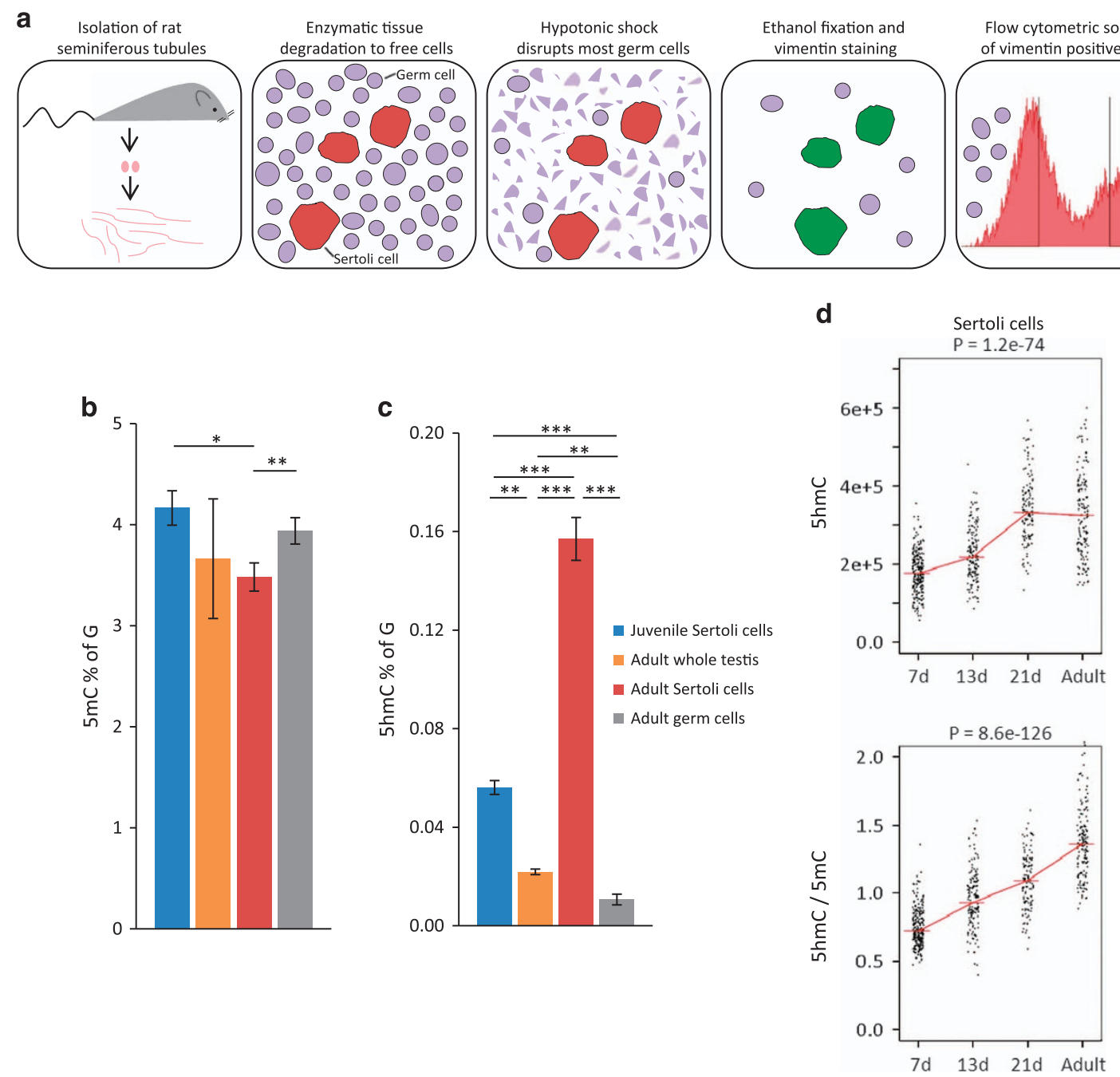

Figure 1 Isolation of adult Sertoli cells and quantification of global levels of $5 \mathrm{mC}$ and $5 \mathrm{hmC}$. (a) Schematic overview of the isolation of adult Sertoli cells from whole testis. Quantification of global levels of (b) $5 \mathrm{mC}$ and (c) $5 \mathrm{hmC}$ in Sertoli cells. Mass spectrometric quantification of modified cytosines as percentage of guanine. Student's $t$-test, ${ }^{* * *} P$-value $\leq 0.0001$; ${ }^{* *} P$-value $\leq 0.005$; ${ }^{*} P$-value $\leq 0.01$; error bars represent s.d.; $n=3$. (d) Immunofluorescence quantification of $5 \mathrm{hmC}$ and $5 \mathrm{hmC} / 5 \mathrm{mC}$, respectively, at ages 7 days, 13 days, 21 days and 15 weeks (adult). Signal intensity measured relative to DAPI intensity (arbitrary units), see Supplementary Figure S2 for details; $n=250-300$ per time point. 
Sertoli cells are largely absent during the prepubertal period [17]; consequently, many of the genes expressed in Sertoli cells during the period of testis formation are not expressed during later spermatogenesis and vice versa [18].

The dual role of Sertoli cells, that is, formation of the testis before puberty and support of spermatogenesis during and after puberty, and the earlier finding that replicative and post-replicative murine cells exhibit different levels of $5 \mathrm{hmC}$ [5], prompted us to study the $5 \mathrm{hmC}$ distribution in these two cell states. We wanted to investigate whether maturation of Sertoli cells affects global $5 \mathrm{hmC}$ content. Moreover, we sought to explore the difference in genomic distribution of $5 \mathrm{hmC}$ before and after maturation and identify genes characterized by either gain or loss of $5 \mathrm{hmC}$.

\section{Results}

\section{Isolation of Sertoli cells}

In order to ascertain that the density and distribution of $5 \mathrm{hmC}$ reflect the physiological state in the organism, we used primary isolates of Sertoli cells without extended culture or proliferation in vitro. Adult Sertoli cells were isolated using enzymatic tissue digestion and hypotonic shock, followed by fluorescence-activated cell sorting (Figure 1a and Supplementary Figure S1). The cells were labeled for vimentin, which in the context of the seminiferous tubule is a marker for Sertoli cells (Supplementary Figure S1B), and sorted on the basis of signal intensity (Supplementary Figure S1C). In order to estimate cell purity, the sorted cells were labeled with SOX9, an additional Sertoli cell-specific marker, which localized to the vimentin-stained cells (Supplementary Figure S1E). The purity of the sorted Sertoli cell fraction was consistently 95\% (Supplementary Figure S1D).

\section{The global level of $5 \mathrm{hm}$ C increases during rat Sertoli cell maturation}

Using liquid chromatography-tandem mass spectrometry (LC-MS/MS) we determined the global levels of genomic $5 \mathrm{mC}$ and $5 \mathrm{hmC}$ in rat Sertoli cells from juvenile (7 days) and adult animals (Figure $1 b$ and $c$ ). The amount of $5 \mathrm{mC}$ was lower in adult than in juvenile Sertoli cells, $3.5 \% 5 \mathrm{mC}$ of G compared to $4.2 \% 5 \mathrm{mC}$ of $\mathrm{G}$, a decrease of $\sim 16.4 \%$. In the adult animals, germ cells exhibited a $13.1 \%$ higher level of $5 \mathrm{mC}$ than Sertoli cells (Figure 1b). As for $5 \mathrm{hmC}$, DNA derived from adult Sertoli cells contained considerably more $5 \mathrm{hmC}$ than DNA from juvenile Sertoli cells (Figure 1c). We observed a 2.8 -fold increase in $5 \mathrm{hmC}$ density during puberty in Sertoli cells, from 0.056 to $0.157 \%$ $5 \mathrm{hmC}$ of $\mathrm{G}$.

The level of $5 \mathrm{hmC}$ in adult Sertoli cells $(0.157 \%$ $5 \mathrm{hmC}$ of $\mathrm{G})$ exceeded the level of the whole testis $(0.022 \% 5 \mathrm{hmC}$ of $\mathrm{G})$ by $\sim 7.2$ times and the level of adult germ cells $(0.011 \% 5 \mathrm{hmC}$ of $\mathrm{G})$ by $\sim 14.7$ times. The level of $5 \mathrm{hmC}$ in adult germ cells was only $48.7 \%$ of that of the level of the adult whole testis. Sertoli cells make up a very small proportion of the cells in the seminiferous tubule of adult testis. Quantitative data from mouse show that Sertoli cells represent $\sim 2 \%$ of the cells in the adult seminiferous tubule [19]. The higher $5 \mathrm{hmC}$ level in whole testis as compared to germ cells alone is likely due to the contribution from Sertoli cells.

\section{$5 \mathrm{hmC}$ increase confirmed using immunofluorescence}

The increase in $5 \mathrm{hmC}$ density during puberty was further confirmed by immunofluorescence quantification (Figure 1d). The $5 \mathrm{hmC}$-specific fluorescence increased in Sertoli cells from day 7 to day 21, and remained unchanged from 21 days until adulthood; this pattern differed from the pattern observed in other testicular cell types, including peritubular cells and spermatogonia, which did not display increased 5hmC-specific fluorescence (Supplementary Figure S2 displays all cell types analyzed). In addition, while the levels of $5 \mathrm{hmC}$ in Sertoli cells remained comparable from 21 days to adulthood, peritubular cells, spermatogonia and the emerging spermatocytes displayed reduced $5 \mathrm{hmC}$ levels between these time points. Notably, the variation of $5 \mathrm{hmC}$ levels in the Sertoli cells was increased in adult compared to juvenile animals.

\section{Mapping of $5 \mathrm{hmC}$ in the juvenile and adult Sertoli cell genome}

Genomic DNA was isolated from juvenile and adult rat Sertoli cells. The DNA containing $5 \mathrm{hmC}$ was chemically labeled, pulled down and sequenced as described in Materials and methods. The sequenced reads were then mapped to the rat genome and peaks were called using SICER, see Figure 2a for a schematic representation. There were 84890 and 56074 peaks in the adult and $7 \mathrm{~d}$ samples, respectively, which resulted in a total of 98208 identified peaks in the combined data. Of these, 43870 peaks were intragenic and localized to 10725 genes (Table 1). The $5 \mathrm{hmC}$ peaks were classified into three groups: peaks that were lost during maturation (9 465); peaks that were gained during maturation (10 116); and peaks that were maintained and appeared in both age groups (78 627). 
a
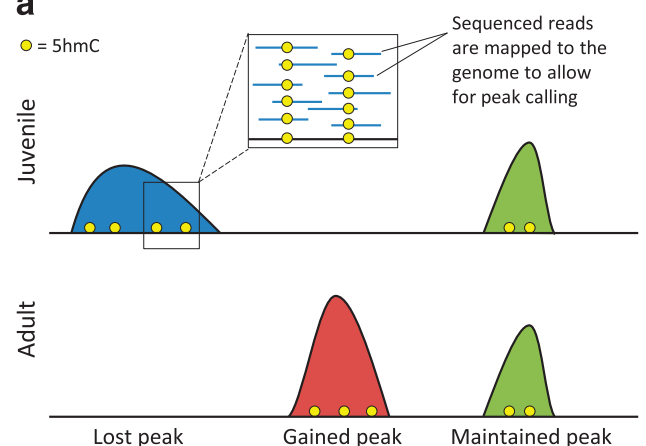

c

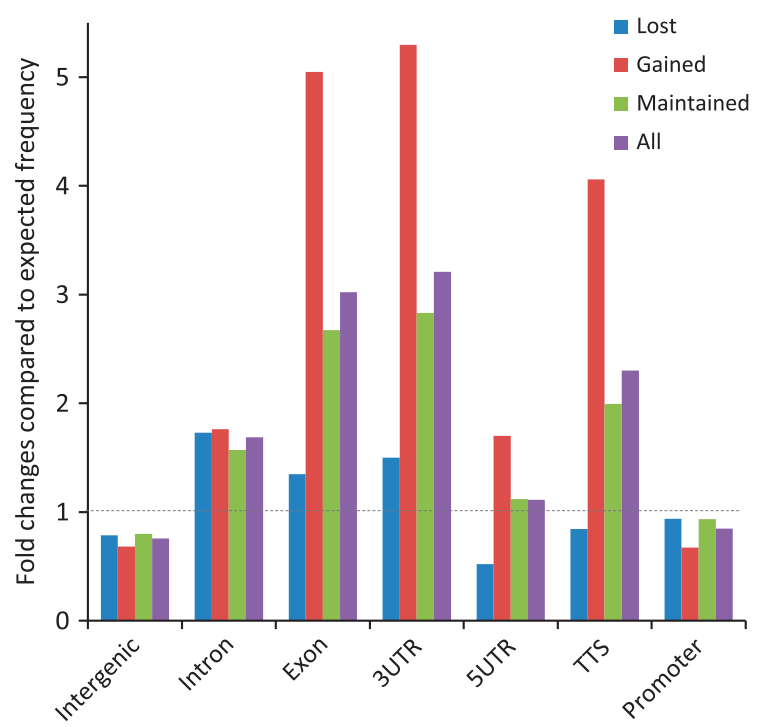

\section{b}

Lost
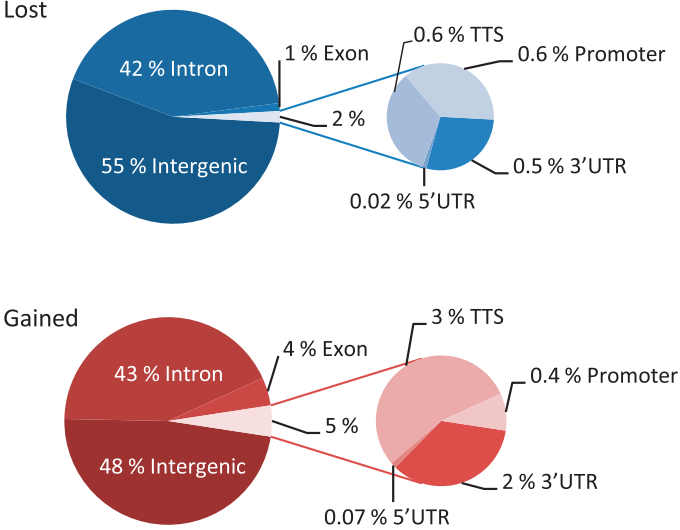

Maintained

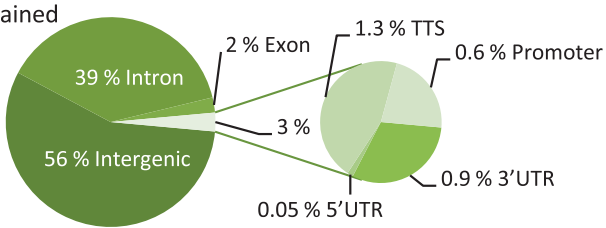

All

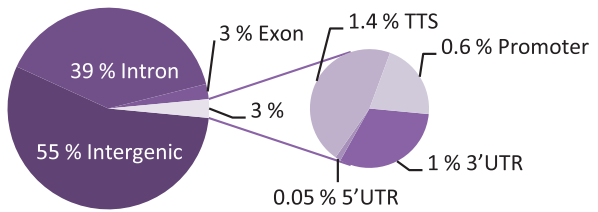

d

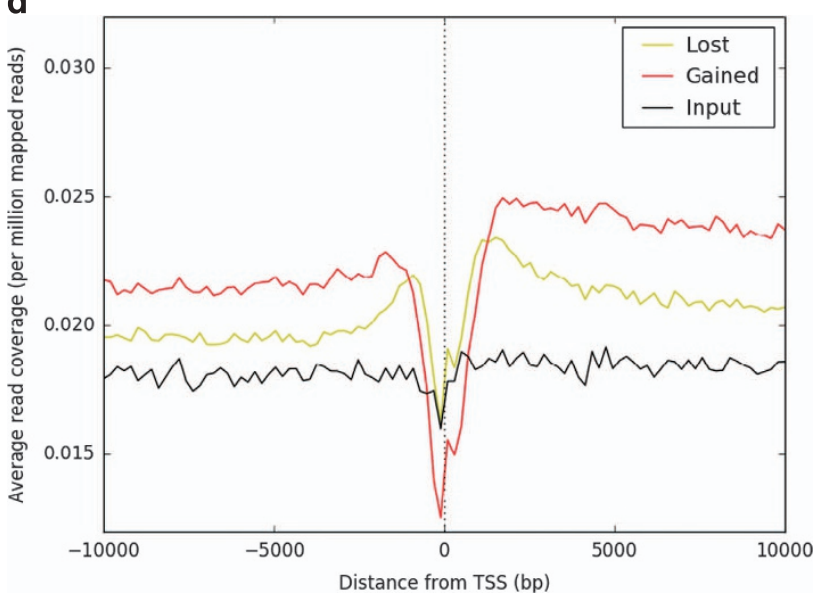

e

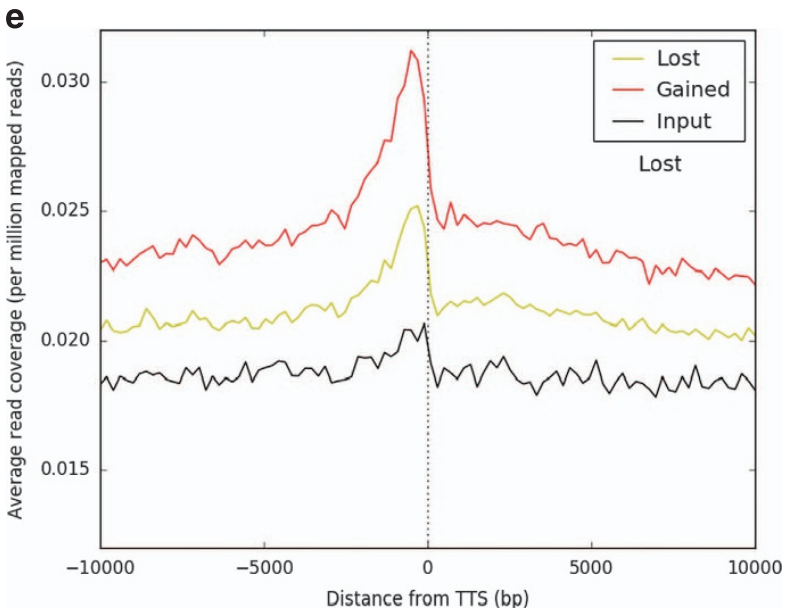

Figure 2 Mapping the sequenced reads to the rat genome. (a) Schematic overview, sequenced reads are mapped to the genome to allow for peak calling; peaks are lost, gained or maintained as juvenile Sertoli cells mature into adulthood. (b) Representation of the peaks in the gene regions. (c) Fold changes compared to the expected frequency of each gene region in the rat genome; expected value is 1. (d) Average read coverage around the TSS and (e) transcription termination site (TTS). The input sample was generated by pooling equal amounts from each of the six input samples. 
Table 1 Sequencing and mapping results

\begin{tabular}{lcccc}
\hline & Peaks & Intragenic peaks & Intragenic peaks (\%) & Genes \\
\hline Lost & 9465 & 4258 & 45 & 1927 \\
Gained & 10116 & 5275 & 52 & 3284 \\
Maintained & 78627 & 34337 & 44 & 9559 \\
Total & 98208 & 43870 & 45 & 10725 \\
\hline
\end{tabular}

Peaks that only appear in the juvenile animals and are lost during maturation are designated Lost; peaks that are gained during maturation and appear only in the adult animals are designated Gained; and peaks that appear in both ages of animals are designated Maintained. Number of identified peaks, number and percentage of intragenic peaks, number of genes that contain the peaks.

The number of peaks that mapped to intragenic regions and were lost was 4258 ; the number of intragenic peaks that were gained was 5 275; and there were 34337 intragenic peaks that were maintained during maturation. The numbers of input and filtered reads are shown in Supplementary Table S1. These counts are in agreement with data from previous studies using this $5 \mathrm{hmC}$ sequencing technology [20].

\section{Gene region enrichment differs among peak groups}

The three peak groups we distinguished, that is peaks lost, gained and maintained during maturation, differed in the proportion of peaks that mapped to different gene regions. The gained peaks, which were only present in the adult samples, were more enriched in gene regions other than intronic and intergenic (Figure 2b). Figure 2c shows the fold changes compared to the expected frequency of each gene region in the genome. The density of $5 \mathrm{hmC}$ in intergenic regions was lower than expected in all peak groups. The differences among the groups were small in the intergenic and intronic regions. All, but particularly the gained, $5 \mathrm{hmC}$ peaks were under-represented at promoter regions. In exons, 3' untranslated regions (UTR), 5'UTR and transcription termination sites, the gained $5 \mathrm{hmC}$ peaks exhibited a markedly higher fold change from expected than the maintained and the lost $5 \mathrm{hmC}$ peaks. For this latter group, $5 \mathrm{hmC}$ is under-represented in the category $5^{\prime}$ UTR. The average read coverage in the vicinity of the transcription start site (TSS) and the transcription termination site is shown in Figure 2d and e. We observed a drop in $5 \mathrm{hmC}$ levels at the TSS and an increase in $5 \mathrm{hmC}$ levels immediately upstream of the transcription termination site for both lost and gained peaks.

\section{Peak length and peak count vary among peak groups}

The length of the $5 \mathrm{hmC}$ peaks differed among the groups. The peaks that were lost during maturation were significantly longer than both the peaks that were gained and the peaks that were maintained
(Supplementary Figure S3A). The number of peaks per gene also differed among the groups (Supplementary Figure S3B). Genes that lost $5 \mathrm{hmC}$ compared to genes that gained $5 \mathrm{hmC}$ contained on average more peaks; the genes with maintained peaks had more peaks on average than genes in the other groups. Supplementary Figure S3C shows the mean of all $\log 2$-count per million $(\log 2 \mathrm{CPM})$ peak intensities per chromosome for the lost, maintained and gained groups. For all chromosomes, except chromosome 12, the lost group shows higher intensity than the gained and maintained groups. Chromosome Y's lost group (20 peaks) shows much higher intensity on average compared to the other chromosomes. Supplementary Figure S3D and E indicates the percentage of gained and lost $5 \mathrm{mC}$ and $5 \mathrm{hmC}$ peaks per chromosome. The $\mathrm{Y}$ chromosome both loses and gains $5 \mathrm{mC}$. However, it does not gain any $5 \mathrm{hmC}$ during maturation, but there is a substantial loss of $5 \mathrm{hmC}$.

Lost and gained $5 \mathrm{hmC}$ is enriched in genes belonging to different functional pathways in juvenile and adult

Sertoli cells

Gene ontology analyses using the DAVID database on genes with lost or gained $5 \mathrm{hmC}$ peaks revealed that these two peak groups were associated with genes involved in distinct cellular pathways (Figure 3).

Ten of twenty pathway clusters with the highest enrichment scores in the lost and gained $5 \mathrm{hmC}$ peak groups are shown in Figure $3 \mathrm{a}$ and $\mathrm{b}$, and the complete set of pathways is listed in Supplementary Table S2. The $5 \mathrm{hmC}$ peaks that were lost during maturation mapped to genes associated with morphogenesis and cell structure (Figure 3a). Genes related to cell adhesion, cell projection, cytoskeleton and localization of the cell displayed high enrichment scores, as did genes related to tube morphogenesis. Corresponding searches on $5 \mathrm{hmC}$ peaks that were gained during Sertoli cell maturation identified pathways associated with transportation, catabolic processes, mitochondrion and endocytosis (Figure 3b). 

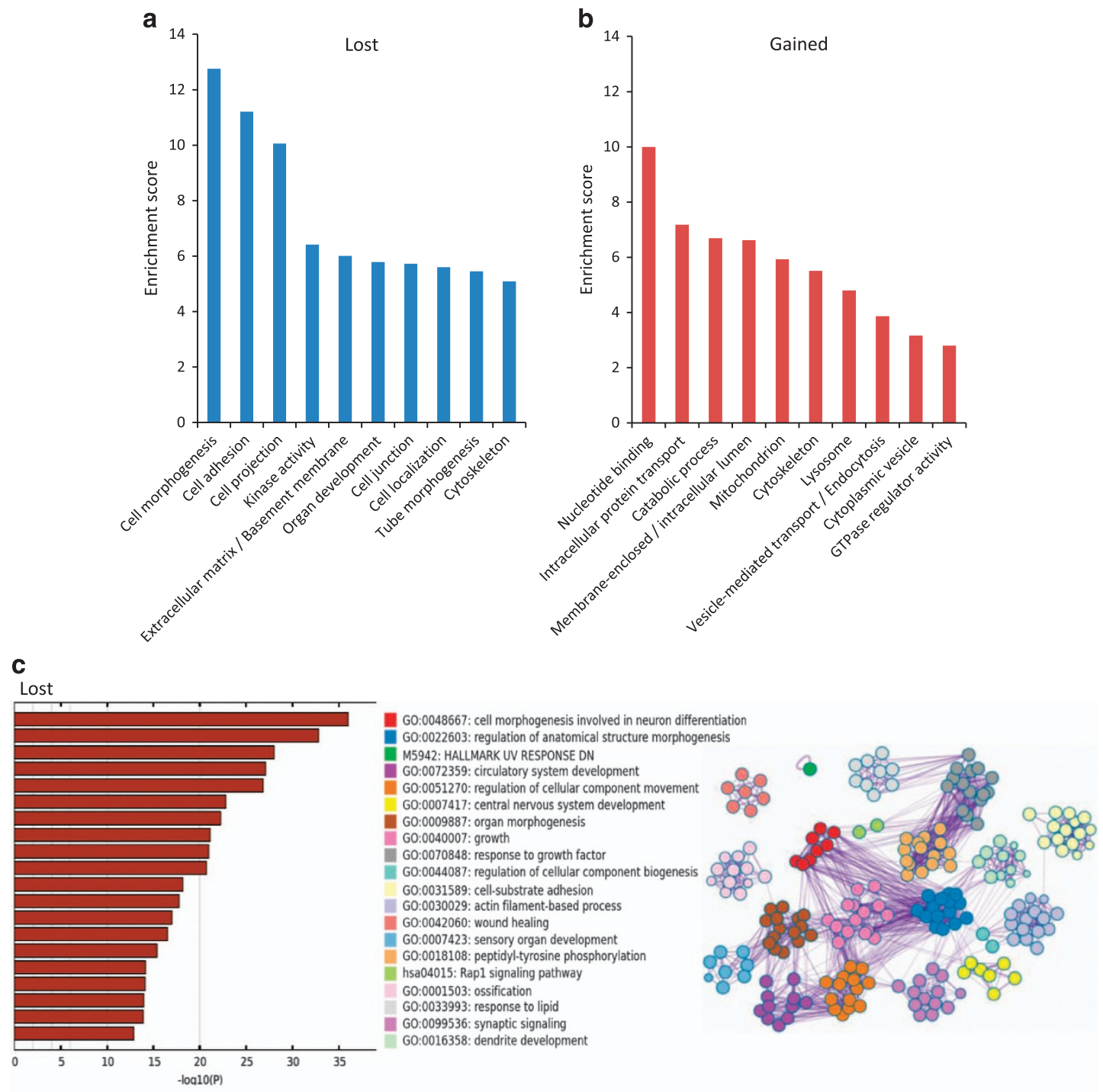

d
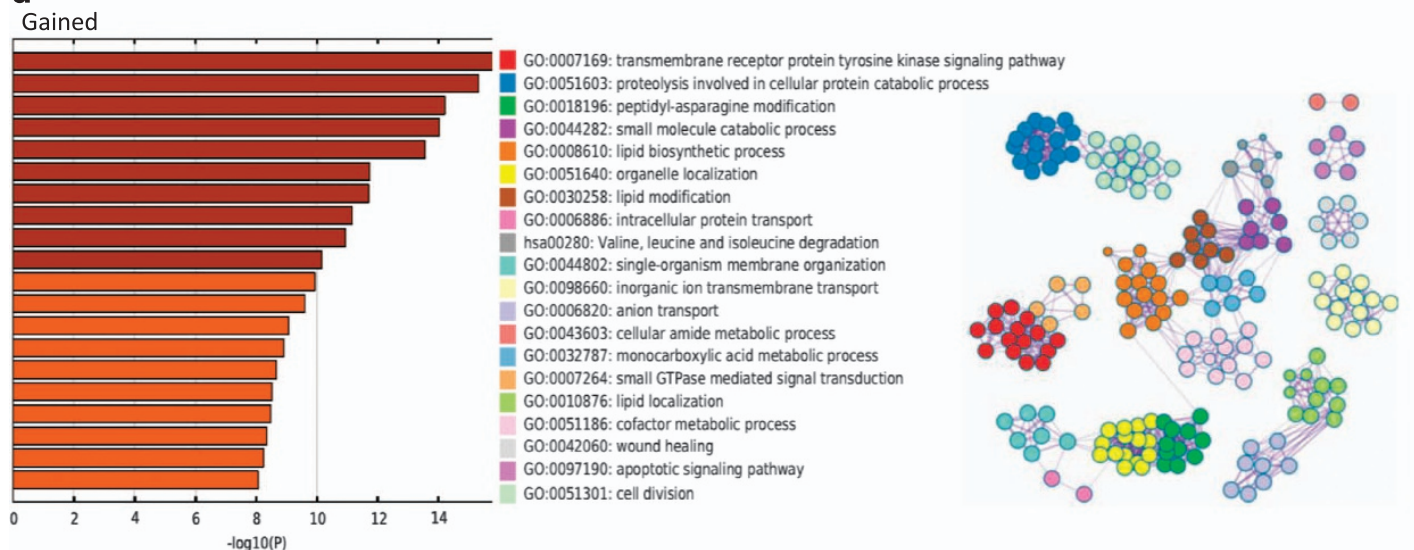

Figure 3 Visualization of the pathways enriched with $5 \mathrm{hmC}$ that is lost or gained during maturation of Sertoli cells. (a) DAVID and (c) Metascape gene ontology searches based on genes that contain $5 \mathrm{hmC}$ peaks that are lost. (b) DAVID and (d) Metascape gene ontology searches based on genes that contain $5 \mathrm{hmC}$ peaks that are gained. Metascape selects up to 10 terms within each of the 20 top-scoring clusters, and then connect all terms pairs with Kappa similarity above 0.3. Network visualized with Cytoscape; each node represents one enriched term; edges link similar terms. Only one term within each cluster is chosen to show its label. $-\log 10(P)$ values higher than 10 are shown in brown bars; lower than 10 are shown in orange. 

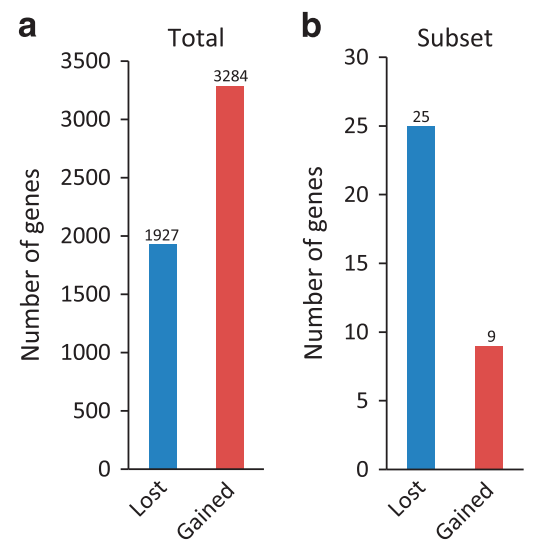

Figure 4 Number of genes that contain $5 \mathrm{hmC}$ that is lost and gained during maturation of Sertoli cells. (a) Total number of genes that lose and gain $5 \mathrm{hmC}$, respectively. (b) Number of genes that lose and gain $5 \mathrm{hmC}$ in the subset of 101 genes that have been found to be highly expressed in immature Sertoli cells.

To confirm these observations, we performed additional analyses using the Metascape database. The results corroborated data obtained using the DAVID database and confirmed a clear dichotomy between enriched pathways in the groups with gained or lost $5 \mathrm{hmC}$ peaks (Figure $3 \mathrm{c}$ and $\mathrm{d}$ ). The pathways enriched in the lost $5 \mathrm{hmC}$ peak group included morphogenesisand development-related terms, whereas the gained $5 \mathrm{hmC}$ peak group was associated with genes involved in metabolic processes and transport. We observed strong connections among cellular pathways related to genes with lost $5 \mathrm{hmC}$ peaks, as visualized by enrichment networks. Database searches for gained $5 \mathrm{hmC}$ peaks gave considerably lower significance scores than searches on lost $5 \mathrm{hmC}$ peaks, indicating a wider distribution of affected pathways.

In order to consider all $5 \mathrm{hmC}$ peaks present in the juvenile animals, we included maintained and lost peaks in a juvenile data set. A corresponding adult data set was created including maintained and gained peaks. These data sets were probed for enriched pathways using gprofileR (Supplementary Figure S4). We observed a substantial overlap in metabolism-related terms between the juvenile and adult data sets, and noted the absence of developmental terms in the adult group.

\section{$5 \mathrm{hmC}$ enrichment in genes that are upregulated in immature Sertoli cells}

We further investigated the presence of $5 \mathrm{hmC}$ modification in genes known to be upregulated in immature Sertoli cells [21] (Supplementary Table S3). Of the 101 upregulated genes identified by Ryser et al. [21], 36 were pulled down for $5 \mathrm{hmC}$ in our experiments.
Interestingly, 25 of these genes contained intragenic $5 \mathrm{hmC}$ peaks that were lost during Sertoli cell maturation. For the total pull-down, there are $70 \%$ more genes that contained gained $5 \mathrm{hmC}$ peaks than lost $5 \mathrm{hmC}$ peaks (see Figure 4a). However, for the subset of 101 genes identified as highly expressed in immature Sertoli cells, $64 \%$ fewer genes contained gained peaks than lost peaks (see Figure $4 b$ ). Hence, there is a significantly larger proportion of genes that lose $5 \mathrm{hmC}$ during maturation among the genes that are highly expressed in immature Sertoli cells than in the total pull-down sample (odds ratio of 4.8 for lost compared to gained; $P=0.00002$, Fisher's exact test). The median number of peaks for this group of 25 highly expressed genes with at least one lost peak is 7 (mean 8). In contrast, the median number of peaks for the group of nine genes that contained gained peaks was 4 (mean 3 ). This reflects the previously mentioned pattern (Supplementary Figure S3): genes with lost peaks have more peaks than other genes.

\section{Discussion}

The pubertal maturation of Sertoli cells is associated with cessation of proliferation, alterations in gene transcription and protein expression, construction of inter-Sertoli cell tight junctions, establishment of the blood-testis barrier and the capacity to sustain spermatogenesis [17, 22]. The functions of adult Sertoli cells that support spermatogenesis are largely absent during the prepubertal period [17]. The maturation of the Sertoli cell is considered to be a step-wise process and failure to undergo an early step may prevent or interfere with subsequent steps [17]. Erroneous maturation of Sertoli cells into the terminally differentiated adult state has been shown to be the cause of reduced fertility in men [17]. Indeed, functionally immature Sertoli cells are observed in men with infertility $[23,24]$.

It has been shown that the presence and state of the germ cells regulate the gene expression of the nurturing Sertoli cells $[25,26]$, and complex interactions between somatic Sertoli cells and germ cells are required for proper spermatogenesis [27]. Sertoli cells in conventional culture do not maintain these crucial Sertoli cell-germ cell interactions, nor do these cells polarize or express tight junctions that are essential for their proper function in vivo [16]. The absence of germ cells induces regression to immature traits in cultured Sertoli cells [17]. Furthermore, global $5 \mathrm{hmC}$ levels are reduced in cultured cells compared to uncultured primary samples, and $5 \mathrm{hmC}$ content is rapidly 
diminished with each passage [6]. In order to avoid spurious effects of cell culture in vitro, we studied primary isolates of Sertoli cells that were enriched with fluorescence-activated cell sorting.

The global level of $5 \mathrm{hmC}$ increases during rat Sertoli cell maturation and gene regions differ in $5 \mathrm{hmC}$ enrichment

We determined the total amount of $5 \mathrm{mC}$ and $5 \mathrm{hmC}$ in rat testis, and found that the variability of $5 \mathrm{mC}$ levels was lower according to cell types than the variability of $5 \mathrm{hmC}$ levels. This pattern of stable $5 \mathrm{mC}$ distribution and tissue-dependent variation in $5 \mathrm{hmC}$ has been previously described $[5,6]$. The level of $5 \mathrm{mC}$ is comparable to data obtained from mouse testis [5]. The level of $5 \mathrm{hmC}$ in adult whole-rat testis $(0.022 \% 5 \mathrm{hmC}$ of $\mathrm{G})$ is also in agreement with previous results obtained from adult mouse testis $(\sim 0.025 \% 5 \mathrm{hmC}$ of G) [5]. We observed a threefold increase of $5 \mathrm{hmC}$ levels in the adult compared to the immature Sertoli cells, which may be related to the post-mitotic state of the Sertoli cells. Indeed, the postnatal day 7 mouse cerebellum, which is characterized by massive cell proliferation, has low $5 \mathrm{hmC}$ levels compared to the adult, non-proliferating cerebellum $[2,8,20]$.

The pattern of $5 \mathrm{hmC}$ levels shown in Figure $1 \mathrm{~d}$ suggests that the $5 \mathrm{hmC}$ level remains stable beyond day 21 of life. At this time point Sertoli cells have lost proliferative ability [28], and formed the inter-Sertoli cell tight junctions that sequester the gonocytes inside of the seminiferous tubules [17]. The tight junctions hinder a direct access to many nutrients and regulatory factors that have to be supplied to the germ cells by the Sertoli cells, constituting the main role of the adult Sertoli cell [17].

Similarly to previously published results, we found that $5 \mathrm{hmC}$ is enriched in gene bodies $[6,8,20,29,30]$. However, we observed that gain or loss of $5 \mathrm{hmC}$ during maturation is associated with different gene regions (Figure $2 \mathrm{~b}$ and $\mathrm{c}$ ). Our results indicate $\mathrm{a}$ reduced $5 \mathrm{hmC}$ enrichment at the TSS, in line with previous findings in adult mouse cerebellum [20], but in contrast to findings in mouse embryonic stem cells, where $5 \mathrm{hmC}$ is enriched at the TSS [13].

The median peak length of lost peaks was significantly longer than that of maintained and gained peaks. Hence, the global increase in $5 \mathrm{hmC}$ level in Sertoli cells is accompanied by a shift to shorter peaks.

Functional pathways enriched with $5 \mathrm{hm} C$ peaks in juvenile and adult Sertoli cells coincide with cell state function

The pathways enriched with $5 \mathrm{hmC}$ peaks that are lost during maturation include morphogenesis, development and cell adhesion, which seem to correlate with the function of the rapidly proliferating Sertoli cells in the young rat. Indeed, these gene ontology categories correspond with those previously found to be upregulated in prepubertal Sertoli cells [21]. Gene pathways pertaining to development or morphogenesis were not enriched in the fraction of genes that gained $5 \mathrm{hmC}$. During the time between 9 and 22 days of age, the expression of tissue development- and neurogenesis-related genes was found to decrease in rat Sertoli cells [21]. The high significance values of tube development, cell localization and projection are particularly interesting in this context, since the Sertoli cell is considered to determine the structure of the emerging seminiferous tubule [31].

Whereas the proliferating prepubertal Sertoli cells seem to lose $5 \mathrm{hmC}$ enrichment overwhelmingly in development- and structure-associated genes, the pathways that gain $5 \mathrm{hmC}$ during maturation are associated with nucleotide binding, transportation, catabolic and lipid processes, mitochondrion, cytoskeleton and vesicle-mediated transportation. Adult Sertoli cells are known to have a diverse and highly active metabolism with an abundance of mitochondria, and a high expression of metabolism-related genes [31]; this is partly due to the processing of spermatid cytoplasm and the abundance of lipids this entails [32]. It is therefore interesting that multiple pathways associated with metabolism, lipids and mitochondrion were identified as $5 \mathrm{hmC}$-gaining pathways in the adult Sertoli cell. In fact, gene expression data for adult Sertoli cells have shown that the largest proportion of expressed genes was associated with metabolism, with a relatively large number of genes expressed in the transport category; moreover, that Sertoli cells express multiple enzymes involved in general metabolism, lipid metabolism and nucleotide metabolism [16].

Genes related to the cytoskeleton acquire $5 \mathrm{hmC}$ peaks during maturation. Cells rely on the cytoskeleton for cell shape and polarity, and for sorting and transporting proteins. However, the terminally differentiated Sertoli cells construct one of the most intricately elaborate cytoskeletons known, which enables these cells to carry out functions that are essential to male fertility, including anchoring germ cells and translocating these toward the lumen of the seminiferous tubule, often through the very cell body of the Sertoli cells [33]. The cyclic process of the spermatogenesis entails a continuous reshaping of the Sertoli cells and requires a dynamic cytoskeleton [33]. Cytoskeleton disruption results in defects in sperm release and cytoplasm phagocytosis [34]. The constant 
remodeling of the cell shape also requires the presence of proteases, a group of enzymes known to be highly expressed in adult Sertoli cells [31]; genes coding for proteases, however, did not gain $5 \mathrm{hmC}$ peaks in our experiments.

Genes coding for lysosome and vesicle-associated pathways gain $5 \mathrm{hmC}$ peaks during Sertoli cell maturation. This finding is interesting considering that the Sertoli cell is phagocytotic; the final stage of spermiogenesis involves the removal of spermatid cytoplasm and phagocytosis of residual bodies. These processes as well as the continuous engulfing of apoptotic germ cells lead to the formation of numerous lysosomes and multivesicular bodies in the cytoplasm of Sertoli cells [31].

When using gprofileR to compare the juvenile data set comprising maintained and lost peaks, with the adult data set comprising maintained and gained peaks (Supplementary Figure S4), an overlap in metabolismrelated pathways appear. The juvenile animals display $5 \mathrm{hmC}$ in metabolism-related genes, but these pathways are not discernible when restricting the analysis to peaks that are lost. Hence, when the maintained peaks are included in the analysis it is evident that juvenile animals also exhibit $5 \mathrm{hmC}$ in genes associated with metabolism. Cells at all states possess an inherent metabolism, if $5 \mathrm{hmC}$ content is indicative of active transcription it is not surprising that $5 \mathrm{hmC}$ is present in genes belonging to metabolism pathways in both immature and mature Sertoli cells. Indeed, the majority of peaks are maintained, reflecting the fact that every cell carries out general physiological metabolism vital for basic cellular functions. The genes necessary for these functions would not be affected by the maturation state of the cell. In additionddition, the adult animals do not display $5 \mathrm{hmC}$ enrichment in development-associated pathways. The consistent absence of development pathways in the adult data set confirms this pattern of $5 \mathrm{hmC}$ enrichment in active genes.

\section{Maturational loss of $5 \mathrm{hmC}$ in genes that are upregulated in immature Sertoli cells}

The number of genes with $5 \mathrm{hmC}$ peaks that are gained or lost during maturation would predict that more genes would gain peaks than would lose peaks. In fact, $70 \%$ more genes gained than lost $5 \mathrm{hmC}$ (Table 1 and Figure 4). However, for the genes that Ryser et al. [21] found to be highly upregulated in juvenile Sertoli cells, fewer genes gained (nine genes) than lost (25 genes) 5hmC (Supplementary Table S3). Among the genes that were found to lose $5 \mathrm{hmC}$ is Vasn/ATIA (loses one out of two peaks); male $A T I A^{-1-}$ mice have markedly increased apoptosis of the seminiferous tubule and impaired fertility [35]. NCAM is another gene that was found to be upregulated in immature Sertoli cells and lost $5 \mathrm{hmC}$ peaks during maturation (loses three out of nine peaks); NCAM codes for a cell adhesion molecule that has been identified as an important factor in gonocyte-Sertoli cell adhesion in neonatal rats [36]. A third illustrative example is Col4al (loses three out of nine peaks), a component of type IV collagen that constitutes the main component of basement membranes; a decrease in the murine expression of Col4al has been shown to be associated with failure to maintain testicular cord integrity. Col4al is regulated by $W t 1$ that shows up in our data set with 2 maintained peaks and 1 that is lost [37].

Analogous to our results, evidence has emerged that $5 \mathrm{hmC}$ is enriched in the gene bodies of actively transcribed genes $[1,6,9,14,20,30]$. $5 \mathrm{hmC}$ cannot be bound by the transcriptionally repressive methyl-CpG binding domain proteins $[38,39]$, indicating that presence of $5 \mathrm{hmC}$ at the gene body regulates transcription rates by inhibiting the binding of repressive proteins and altering the accessibility of chromatin to the transcription machinery.

It has been suggested that $5 \mathrm{hmC}$ influences tissuespecific gene expression during development. Genes that acquired $5 \mathrm{hmC}$ between the age of 7 days and adult in mouse cerebellum were involved in cerebellum development and various neuronal functions [8]. Accumulation of $5 \mathrm{hmC}$ in the mouse brain during aging has been reported previously with both aging in itself as well as developmental reprogramming as suggested causes [8]. It has also been shown that $5 \mathrm{hmC}$ accumulates in the developing mouse cerebellum until adulthood and then becomes stable [20]. However, a recent report demonstrated that $5 \mathrm{hmC}$ is reduced in $\mathrm{T}$ cells during their lifetime [40]. Future research dedicated to epigenetic modifications in Sertoli cells should broaden the time frame to include more time points in order to further elucidate the possible fluctuations in $5 \mathrm{hmC}$ during the entire lifespan of the animal.

All TET proteins are expressed in the juvenile rat testes [41]. Identifying the TET variant that is responsible for the observed increase in $5 \mathrm{hmC}$ would give important information about the nature of this maturation.

Our results indicate that a global increase and dynamic redistribution of $5 \mathrm{hmC}$ occurs during the maturation of the Sertoli cells. The $5 \mathrm{hmC}$ level ceases to increase when Sertoli cells have acquired all the 
features of the adult cell. Many of the genes expressed in Sertoli cells during testis formation are silenced during spermatogenesis. We show that this change in gene expression is accompanied by a shift in genomic $5 \mathrm{hmC}$ distribution, with $5 \mathrm{hmC}$ being enriched in actively transcribed genes that define the cell state.

\section{Materials and Methods}

\begin{abstract}
Animals
Adult male Wistar-Hannover rats were obtained from the section for Comparative Medicine at the Oslo University Hospital, Ullevål. Prepubertal Wistar-Hannover rats were 7-day-old and adult rats were 15-week-old. Animals were purchased from the Møllegaard Breeding and Research Center, Skensved, Denmark, and housed at the Section for Comparative Medicine, Oslo University Hospital, Ullevål. All procedures were approved by the Norwegian Animal Research Authority (Vit 1033), in accordance with the European Convention for the Protection of Vertebrate Animals used for Experimental and other Scientific Purposes (ETS no.123).
\end{abstract}

\section{Sertoli cell isolation}

Adult Sertoli cells were isolated according to a method described earlier [42] with minor changes (Supplementary Figure S1A). Briefly, testes were excised and placed in $1 \times$ HBSS (Hank's Balanced Salt Solution, cat\#14185-052, adjusted to $\mathrm{pH} 7.4$ with sodium bicarbonate, cat\#25080-094, Life Technologies, Oslo, Norway). Testes were decapsulated and subjected to enzymatic digestion (collagenase solution (C2674, Sigma-Aldrich, St Louis, MO, USA), trypsin (T5266, Sigma), hyaluronidase (H6254, Sigma), DNaseI (D5025, Sigma)) and washing steps to free the tubular cells by breaking down the interstitial matrix. All enzyme solutions were dissolved in HBSS and the washing steps were carried out in HBSS. After isolation, cells were fixed by suspension in ice-cold $70 \%$ ethanol and placed in freezer at $-70^{\circ} \mathrm{C}$. Seminiferous tubules from juvenile 7-day-old rats were obtained by testis excision, decapsulation and washing in HBSS. At the age of 6 days, the seminiferous tubule of the rat contains on average 36.0 Sertoli cells and 1.5 spermatogonia [43]. This entails that $96 \%$ of the cells in the seminiferous tubule are Sertoli cells at this age. At the age of 9 days, the Sertoli cells constitute $94 \%$ of the seminiferous tubule cells [43].

In order to further increase the purity of the isolated Sertoli cells, the samples were labeled for vimentin (Supplementary Figure S1B) and sorted with fluorescence-activated cell sorting (FACS). Ethanol-fixed adult Sertoli cells from the cell isolate described above were transferred to $15 \mathrm{ml}$ tubes and incubation buffer (PBS with $0.1 \%$ Tween 20 and $0.5 \%$ bovine serum albumin) was added. The cells were rinsed twice in incubation buffer and then blocked in the incubation buffer for $10 \mathrm{~min}$ at room temperature. Primary antibody was added (vimentin 1:50, Sigma-Aldrich Cat\# V6630) and incubated for $1 \mathrm{~h}$ at room temperature. After three washes, secondary antibody was added (Alexa Fluor 488 goat anti-mouse 1:500, Invitrogen Cat\# A-11029) and the cells incubated for $30 \mathrm{~min}$ at room temperature. Cells were rinsed twice and then filtered through a cell strainer cap of polystyrene tubes $(75 \mu \mathrm{m}$, VWR Cat\# 352235). The cells were then sorted using a FacsAria II with the Diva 6 software (BD Biosciences, San Jose, CA, USA, Supplementary Figure S1C). The vimentin-positive and -negative cell fractions were collected during sorting.

\section{FACS validation}

To verify that vimentin-positive cells are Sertoli cells, the sorted vimentin-positive and -negative fractions were stained with SOX9 as an additional Sertoli cell marker [44]. Briefly, 20000 sorted cells in $200 \mu \mathrm{l}$ PBS buffer were applied to microscope slides with a cytospin centrifuge (1 000 r.p.m., $5 \mathrm{~min}$ ). The slides were washed twice with TBST (50 mм Tris, $150 \mathrm{~mm} \mathrm{NaCl}$, pH 7.5 with $0.05 \%$ Tween 20) and blocked with $5 \%$ bovine serum albumin in TBST for $60 \mathrm{~min}$. SOX9 antiserum (Sigma, HPA001758, 1:250) in blocking solution was added and incubated for $60 \mathrm{~min}$ at $25^{\circ} \mathrm{C}$. The cells were washed three times for $10 \mathrm{~min}$ with TBST and then incubated with the secondary antibody (goat anti-rabbit-Alexa 594, 1:500, Life Technologies) in blocking solution for $60 \mathrm{~min}$ at $25^{\circ} \mathrm{C}$. Following two washes with TBST, the slides were incubated for $10 \mathrm{~min}$ with $5 \mu \mathrm{g} \mathrm{ml} \mathrm{m}^{-1}$ 4,6-diamidino-2-phenylindole (DAPI). The samples were then mounted with Mowiol (Calbiochem, Sigma-Aldrich) and dried in the dark for $12 \mathrm{~h}$. Slides were observed with an Axio Observer. Z1 Axio inverted microscope (Carl Zeiss, Oslo, Norway) and quantified using AxioVision Software Release 4.8 (Carl Zeiss). The cell isolate obtained had a purity of at least $95 \%$ (Supplementary Figure S1D and E).

\section{Quantification of DNA modifications by LC-MS/MS}

Genomic DNA was enzymatically hydrolyzed to nucleosides essentially as described in [45], added 3 volumes of methanol and centrifuged $\left(16000 \mathrm{~g}, 30 \mathrm{~min}, 4^{\circ} \mathrm{C}\right)$. The supernatants were dried and dissolved in $50 \mu 15 \%$ methanol in water $(\mathrm{v} / \mathrm{v})$ for LC-MS/MS analysis of the deoxynucleoside $5 \mathrm{hm}(\mathrm{dC})$. A portion of each sample was diluted for the quantification of $5 \mathrm{~m}(\mathrm{dC})$ and unmodified deoxynucleosides $\mathrm{dA}, \mathrm{dC}, \mathrm{dG}$ and $\mathrm{dT}$. Chromatographic separation was performed on a Shimadzu Prominence HPLC system (Shimadzu, Kyoto, Japan) with an Ascentis Express C18 $150 \times 2.1 \mathrm{~mm}$ ID $(2.7 \mu \mathrm{m})$ column equipped with an Ascentis Express C18 $5 \times 2.1 \mathrm{~mm}$ ID $(2.7 \mu \mathrm{m})$ guard column (Sigma-Aldrich). The mobile phase consisted of water and methanol (both added $0.1 \%$ formic acid), for $5 \mathrm{~m}(\mathrm{dC})$ and $5 \mathrm{hm}(\mathrm{dC})$, starting with a 5 -min gradient of $5-60 \%$ methanol, followed by $6 \mathrm{~min}$ re-equilibration with $5 \%$ methanol, and for unmodified nucleosides maintained isocratically with $20 \%$ methanol. Mass spectrometric detection was performed using an API5000 triple quadrupole (AB Sciex, Oslo, Norway) operating in positive electrospray ionization mode monitoring the mass transitions 258.1/ 142.1 (5hm(dC)), 242.1/ 126.1 (5 m(dC)), 252.1/136.1 (dA), 228.1/112.1 (dC), 268.1/152.1 (dG) and 243.1/127.1 (dT). Statistical analysis of LC-MS/MS data was performed using one-way analysis of variance with Dunnett's post test, Graphpad Prism version 5.00 (San Diego, CA, USA).

\section{Immunohistochemistry}

Organs were excised and immediately placed in $10 \%$ neutralbuffered formalin. After dehydration and paraffin-embedding 
the organ blocks were cut into $4 \mu \mathrm{m}$ sections and allowed to dry. The sections were warmed at $60^{\circ} \mathrm{C}$ for $1 \mathrm{~h}$, and then deparaffinized in Clear Rite 3 (Thermo Scientific, Waltham, MA, USA) and rehydrated in a series of $100-70 \%$ ethanol. Epitope retrieval was carried out in heated Tris-EDTA buffer (10 mm Tris, $5 \mathrm{~mm}$ EDTA, $\mathrm{pH}$ 9). After incubation in PBST $(0.1 \%$ Tween 20$)$ for $10 \mathrm{~min}$, the sections were blocked $(5 \%$ bovine serum albumin, 5\% goat serum in PBST) for $30 \mathrm{~min}$. Primary antibodies (Vimentin 1:50, Sigma-Aldrich Cat\# V6630; 5hmC 1:200, Active motif, La Hulpe, Belgium, Cat\# 39769; $5 \mathrm{mC}$ 1:200, Diagenode, Liege, Belgium, Cat\# MAb-081-100) were added and the sections incubated at $4{ }^{\circ} \mathrm{C}$ overnight. After three washes, secondary antibodies were added (Alexa Fluor 488 goat anti-mouse 1:500, Invitrogen Cat\# A-11029; Alexa Fluor 594 goat anti-rabbit 1:500, Invitrogen Cat\# A-11012) and incubated for $30 \mathrm{~min}$ at room temperature. For DNA counterstaining, DAPI $\left(1 \mu \mathrm{g} \mathrm{ml} \mathrm{m}^{-1}\right)$ was used and sections were covered with mounting medium (Dako, Agilent Technologies, Santa Clara, CA, USA, Cat\# S3023).

\section{Quantification of $5 \mathrm{mC}$-specific and $5 \mathrm{hmC}$-specific fluorescence intensity}

Fluorescence images were captured using an Axioplan2 epifluorescence microscope (Carl Zeiss) fitted with fluorescence filters for fluorescein isothiocyanate, TexasRed, and DAPI, and a SPOT RT digital camera (Diagnostic Instruments, Sterling Heights, MI, USA). We tested the linearity of optical density measurements obtained with the instrument using the FocalCheck \#1 slide (Life Technologies), which contains fluorescent beads of linearly increasing dye intensity. Expected and measured integrated density of the beads were highly correlated $\left(R^{2}=0.97\right)$. Testicular sections from all developmental stages (days 7, 13, 21 and adult) were mounted on the same microscope slide to allow direct comparison across stages. Slides were stained under standardized conditions (see above). For measurement of nuclear optical density, images of 10-20 high-power fields per stage were captured using strictly identical exposure time for the three fluorescence channels. Exposure times were initially determined for the whole experiment so that no area of the image was overexposed, in order to allow precise quantification of optical density. Monochrome images of red, green and blue channels were captured and imported in Image J (National Institutes of Health, Bethesda, MD, USA, version $1.47 \mathrm{v})$. In ImageJ, while viewing nuclei in the DAPI channel, the Cell Magic Wand tool of Theo Walker was used to mark the perimeter of 250-300 nuclei per image. The following cell types were distinguished based on their position in the seminiferous tubuli, nuclear shape and chromatin texture: peritubular cells, Sertoli cells, spermatogonia and spermatocytes. The integrated optical density of the annotated nuclei was measured in ImageJ and further analyzed in $\mathrm{R}$ (version 3.1.3).

\section{5 hmC pull-down}

We performed $5 \mathrm{hmC}$ pull-down and chemical labeling of genomic DNA using the hMe-SEAL method described by Song et al. [20]. An amount of $25 \mathrm{ng}$ of each sample was subjected to Illumina's Nextera Tagmentation reaction at $55^{\circ} \mathrm{C}$ for $6 \mathrm{~min}$ to simultaneously fragment and add adapters to the DNA. Then,
$100 \mathrm{ng}$ of sonicated ( 500 bp) unmethylated lambda DNA was added as a carrier (added to the binding buffer to limit/eliminate the possibility of the carrier getting tagmented) during the cleanup with a Zymo Clean \& Concentrator Kit (Zymo research, Irvine, CA, USA). $5 \mathrm{hmC}$ in the eluted DNA was labeled in a reaction containing $2 \mu \mathrm{M}$ beta-GT enzyme and $100 \mu \mathrm{M}$ UDP-N3-Glc at $37^{\circ} \mathrm{C}$ for $60 \mathrm{~min}$. The reactions were cleaned again using a Zymo kit and eluted DNA was reacted with $150 \mu \mathrm{M}$ DBCO-biotin at $37^{\circ} \mathrm{C}$ for $90 \mathrm{~min}$. Free biotin reagent was removed by another reaction cleanup using the Zymo kit. Labeled DNA was bound to pre-washed C1 Streptavidin beads for $15 \mathrm{~min}$ at room temperature, and then washed six times with the binding buffer ( $5 \mathrm{~mm}$ Tris $7.5,1 \mathrm{M} \mathrm{NaCl}$, $0.5 \mathrm{~mm}$ EDTA, $0.01 \%$ Tween-20). Bound (5hmC-containing) DNA was then amplified (without elution) using Nextera index PCR for 13 cycles. Beads were removed by a magnetic rack. The resulting DNA was checked for quality/quantity by Agilent Bioanalyzer and Kapa Library Quantitation qPCR, and then mixed in an equimolar library pool for sequencing on the Illumina HiSeq2500. The input sample is an equal mixture of a small portion of all six samples and removed immediately before binding to the $\mathrm{C} 1$ beads. Input was amplified for seven PCR cycles instead of 13 .

\section{Bioinformatic analysis}

Duplicated reads were removed from the raw data using PRINSEQ [46]. The remaining reads were aligned with STAR version 2.2 ( [ref. 47]) to the Rattus norvegicus 6 genome downloaded from UCSC and further processed with samtools [48] and bedtools [49] to produce bam and bed files. To identify enriched regions of $5 \mathrm{hmC}$ in adult, 7 days and input data set, we used the peak caller SICER v1.1 ( [ref. 50]). SICER models the genetic background with random reads based on the input data set, and then identifies clusters of enrichment in a given experimental condition based on this random model. SICER was run with window size $w 200$, fragment size 150, gap size $g 600$ and a false discovery rate (FDR) of 0.01 . Clusters of enrichment from each of the SICER runs were combined to generate a count matrix by counting reads in each region using the read summarization software feature Counts [51]. The count matrix was further processed in $R$ and normalization of the data was done with Voom [52] transform in the limma package [53], which transforms count data to $\log 2$-count per million. The data were linear-fitted and differential enriched regions found using eBayes. On the basis of the results, each enriched region was grouped either to belong to the 7 days (lost), adult (gained; FDR $<0.05$ ) or common (maintained) group (FDR $>0.05)$. The perl script annotatePeaks in HOMER [54] was used to annotate the $5 \mathrm{hmC}$-enriched regions with various gene features like nearest gene, distance to TTS, gene region (5'UTR, promoter, exon, intron, intergenic, $3^{\prime} \mathrm{UTR}$, non-coding) and so on. The annotated regions were merged with values from the statistical analysis and the final data set was ready to be analyzed.

The gene ontology database DAVID was used for pathway analysis (search performed on 3 June 2016; https://david.ncifcrf. gov [55]), as well as Metascape (search performed on 3 June 2016; http://metascape.org [56]). 
Enrichment analysis was performed with gProfileR, an R-package derived from the web-based gProfile toolset [57]. gProfileR was run with a FDR threshold of 0.05 . The enrichment plot was made using the ggplot 2 package in $\mathrm{R}$. We divided each region based on its enrichment into two groups; Juvenile $5 \mathrm{hmC}$ or Adult $5 \mathrm{hmC}$. The category Juvenile $5 \mathrm{hmC}$ includes genes with peaks that are lost and maintained during maturation. The category Adult $5 \mathrm{hmC}$ includes genes with peaks that are maintained and gained during maturation.

\section{Conflict of Interest}

The authors declare no conflict of interest.

\section{Acknowledgements}

We thank Karin Margaretha Gilljam for proofreading. The LC-MS/MS analysis was provided by the Proteomics and Metabolomics Core Facility (PROMEC) and the bioinformatics analysis was provided by the Bioinformatics Core Facility (BioCore), both located at the Norwegian University of Science and Technology (NTNU). PROMEC and BioCore are funded by the Faculty of Medicine at NTNU and Central Norway Regional Health Authority. This work was supported by the Norwegian Research Council, Health South East Region Norway and, specifically, the Research Programme of the EEA/Norway Grants (grant POL/NOR/196258/2013).

\section{Author contributions}

ML, JJ, CH, IS, PS, PF, JAD, HA, MF and AK designed the research; ML, JJ, JMA, CBV, LCD, PF and MF performed the research; ML, JJ, CBV, PS, PF, HA, MF and AK analysed the data; ML, PF, MF and AK wrote the paper. All authors read and commented on the manuscript.

\section{References}

1 Ficz G. New insights into mechanisms that regulate DNA methylation patterning. J Exp Biol 2015; 218: 14-20.

2 Kriaucionis S, Heintz N. The nuclear DNA base 5-hydroxymethylcytosine is present in Purkinje neurons and the brain. Science 2009; 324: 929-930.

3 Ito S, D'Alessio AC, Taranova OV, Hong K, Sowers LC, Zhang Y. Role of Tet proteins in $5 \mathrm{mC}$ to $5 \mathrm{hmC}$ conversion, ES-cell self-renewal and inner cell mass specification. Nature 2010; 466: 1129-1133.

4 Tahiliani M, Koh KP, Shen Y et al. Conversion of 5-methylcytosine to 5-hydroxymethylcytosine in mammalian DNA by MLL partner TET1. Science 2009; 324: 930-935.

5 Globisch D, Munzel M, Muller M et al. Tissue distribution of 5-hydroxymethylcytosine and search for active demethylation intermediates. PLoS ONE 2010; 5: e15367.

6 Nestor CE, Ottaviano R, Reddington J et al. Tissue type is a major modifier of the 5-hydroxymethylcytosine content of human genes. Genome Res 2012; 22: 467-477.
7 Szwagierczak A, Bultmann S, Schmidt CS, Spada F, Leonhardt H. Sensitive enzymatic quantification of 5-hydroxymethylcytosine in genomic DNA. Nucleic Acids Res 2010; 38: e181.

8 Szulwach KE, Li X, Li Y et al. 5-hmC-mediated epigenetic dynamics during postnatal neurodevelopment and aging. Nat Neurosci 2011; 14: 1607-1616.

9 Sun W, Guan M, Li X. 5-hydroxymethylcytosine-mediated DNA demethylation in stem cells and development. Stem Cells Dev 2014; 23: 923-930.

10 Ito S, Shen L, Dai Q et al. Tet proteins can convert 5-methylcytosine to 5-formylcytosine and 5-carboxylcytosine. Science 2011; 333: 1300-1303.

$11 \mathrm{He}$ YF, Li BZ, Li Z et al. Tet-mediated formation of 5-carboxylcytosine and its excision by TDG in mammalian DNA. Science 2011; 333: 1303-1307.

12 Weber AR, Krawczyk C, Robertson AB et al. Biochemical reconstitution of TET1-TDG-BER-dependent active DNA demethylation reveals a highly coordinated mechanism. Nat Commun 2016; 7: 10806.

13 Pastor WA, Pape UJ, Huang Y et al. Genome-wide mapping of 5-hydroxymethylcytosine in embryonic stem cells. Nature 2011; 473: 394-397.

14 Jin SG, Wu X, Li AX, Pfeifer GP. Genomic mapping of 5-hydroxymethylcytosine in the human brain. Nucleic Acids Res 2011; 39: 5015-5024.

15 Griswold MD. The central role of Sertoli cells in spermatogenesis. Semin Cell Dev Biol 1998; 9: 411-416.

16 Neill K. Physiology of Reproduction Third Edition Elsevier. 2006.

17 Sharpe RM, McKinnell C, Kivlin C, Fisher JS. Proliferation and functional maturation of Sertoli cells, and their relevance to disorders of testis function in adulthood. Reproduction 2003; 125: 769-784.

$18 \mathrm{Ka}$ N. Physiology of Reproduction Third Edition Elsevier. 2006.

19 Meistrich ML, Bruce WR, Clermont Y. Cellular composition of fractions of mouse testis cells following velocity sedimentation separation. Exp Cell Res 1973; 79: 213-227.

20 Song CX, Szulwach KE, Fu Y et al. Selective chemical labeling reveals the genome-wide distribution of 5-hydroxymethylcytosine. Nat Biotechnol 2011; 29: 68-72.

21 Ryser S, Glauser D, Vigier $\mathrm{M}$ et al. Gene expression profiling of rat spermatogonia and Sertoli cells reveals signaling pathways from stem cells to niche and testicular cancer cells to surrounding stroma. BMC Genomics 2011; 12: 29 .

22 Lucas TF, Nascimento AR, Pisolato R, Pimenta MT, Lazari MF, Porto CS. Receptors and signaling pathways involved in proliferation and differentiation of Sertoli cells. Spermatogenesis 2014; 4: e28138.

23 Brehm R, Rey R, Kliesch S, Steger K, Marks A, Bergmann M. Mitotic activity of Sertoli cells in adult human testis: an immunohistochemical study to characterize Sertoli cells in testicular cords from patients showing testicular dysgenesis syndrome. Anat Embryol 2006; 211: 223-236. 
24 Steger K, Rey R, Louis F et al. Reversion of the differentiated phenotype and maturation block in Sertoli cells in pathological human testis. Hum Reprod 1999; 14: 136-143.

25 Clifton RJ, O'Donnell L, Robertson DM. Pachytene spermatocytes in co-culture inhibit rat Sertoli cell synthesis of inhibin beta B-subunit and inhibin B but not the inhibin alpha-subunit. $J$ Endocrinol 2002; 172: 565-574.

26 Jegou B. Spermatids are regulators of Sertoli cell function. Ann N Y Acad Sci 1991; 637: 340-353.

27 McLean DJ, Friel PJ, Pouchnik D, Griswold MD. Oligonucleotide microarray analysis of gene expression in follicle-stimulating hormone-treated rat Sertoli cells. $\mathrm{Mol}$ Endocrinol 2002; 16: 2780-2792.

28 Orth JM. Proliferation of Sertoli cells in fetal and postnatal rats: a quantitative autoradiographic study. Anat Record 1982; 203: 485-492.

29 Guo JU, Szulwach KE, Su Y et al. Genome-wide antagonism between 5-hydroxymethylcytosine and DNA methylation in the adult mouse brain. Front Biol 2014; 9: 66-74.

$30 \mathrm{Wu} \mathrm{H}$, D'Alessio AC, Ito $\mathrm{S}$ et al. Genome-wide analysis of 5-hydroxymethylcytosine distribution reveals its dual function in transcriptional regulation in mouse embryonic stem cells. Genes Dev 2011; 25: 679-684.

31 Skinner MK, Griswold MD. Sertoli Cell Biology. USA: Elsevier Inc. 2005.

32 O'Donnell L, Nicholls PK, O'Bryan MK, McLachlan RI, Stanton PG. Spermiation: the process of sperm release. Spermatogenesis 2011; 1: 14-35.

33 Vogl AW, Vaid KS, Guttman JA. The Sertoli cell cytoskeleton. Adv Exp Med Biol 2008; 636: 186-211.

34 O'Donnell L. Mechanisms of spermiogenesis and spermiation and how they are disturbed. Spermatogenesis 2014; 4: e979623.

35 Choksi S, Lin Y, Pobezinskaya Y et al. A HIF-1 target, ATIA, protects cells from apoptosis by modulating the mitochondrial thioredoxin, TRX2. Mol Cell 2011; 42: 597-609.

36 Orth JM, Jester WF Jr. NCAM mediates adhesion between gonocytes and Sertoli cells in cocultures from testes of neonatal rats. J Androl 1995; 16: 389-399.

37 Chen SR, Chen M, Wang XN et al. The Wilms tumor gene, Wt1, maintains testicular cord integrity by regulating the expression of Col4a1 and Col4a2. Biol Reprod 2013; 88: 56.

38 Valinluck V, Tsai HH, Rogstad DK, Burdzy A, Bird A, Sowers LC. Oxidative damage to methyl-CpG sequences inhibits the binding of the methyl-CpG binding domain (MBD) of methyl-CpG binding protein 2 (MeCP2). Nucleic Acids Res 2004; 32: 4100-4108.

39 Jin SG, Kadam S, Pfeifer GP. Examination of the specificity of DNA methylation profiling techniques towards 5-methylcytosine and 5-hydroxymethylcytosine. Nucleic Acids Res 2010; 38: e125.

40 Truong TP, Sakata-Yanagimoto M, Yamada M et al. Age-dependent decrease of dna hydroxymethylation in human T cells. J Clin Exp Hematopathol 2015; 55: 1-6.
$41 \mathrm{Yu} \mathrm{Y,} \mathrm{Fuscoe} \mathrm{JC,} \mathrm{Zhao} \mathrm{C} \mathrm{et} \mathrm{al.} \mathrm{A} \mathrm{rat} \mathrm{RNA-Seq}$ transcriptomic BodyMap across 11 organs and 4 developmental stages. Nat Commun 2014; 5: 3230.

42 Anway MD, Folmer J, Wright WW, Zirkin BR. Isolation of sertoli cells from adult rat testes: an approach to ex vivo studies of Sertoli cell function. Biol Reprod 2003; 68: 996-1002.

43 Clermont Y, Perey B. Quantitative study of the cell population of the seminiferous tubules in immature rats. Am J Anat 1957; 100: 241-267.

44 Frojdman K, Harley VR, Pelliniemi LJ. Sox9 protein in rat sertoli cells is age and stage dependent. Histochem Cell Biol 2000; 113: 31-36.

45 Crain PF. Preparation and enzymatic hydrolysis of DNA and RNA for mass spectrometry. Methods Enzymol 1990; 193: 782-790.

46 Schmieder R, Edwards R. Quality control and preprocessing of metagenomic datasets. Bioinformatics 2011; 27: 863-864.

47 Dobin A, Davis CA, Schlesinger F et al. STAR: ultrafast universal RNA-seq aligner. Bioinformatics 2013; 29: 15-21.

$48 \mathrm{Li} \mathrm{H}$, Handsaker B, Wysoker A et al. The sequence alignment/map format and SAMtools. Bioinformatics 2009; 25: 2078-2079.

49 Quinlan AR, Hall IM. BEDTools: a flexible suite of utilities for comparing genomic features. Bioinformatics 2010; 26: 841-842.

50 Xu S, Grullon S, Ge K, Peng W. Spatial clustering for identification of ChIP-enriched regions (SICER) to map regions of histone methylation patterns in embryonic stem cells. Methods Mol Biol 2014; 1150: 97-111.

51 Liao Y, Smyth GK, Shi W. featureCounts: an efficient general purpose program for assigning sequence reads to genomic features. Bioinformatics 2014; 30: 923-930.

52 Law CW, Chen Y, Shi W, Smyth GK. voom: precision weights unlock linear model analysis tools for RNA-seq read counts. Genome Biol 2014; 15: R29.

53 Ritchie ME, Phipson B, Wu D et al. limma powers differential expression analyses for RNA-sequencing and microarray studies. Nucleic Acids Res 2015; 43: e47.

54 Heinz S, Benner C, Spann N et al. Simple combinations of lineage-determining transcription factors prime cis-regulatory elements required for macrophage and B cell identities. Mol Cell 2010; 38: 576-589.

55 Huang da W, Sherman BT, Lempicki RA. Systematic and integrative analysis of large gene lists using DAVID bioinformatics resources. Nat Protoc 2009; 4: 44-57.

56 Tripathi S, Pohl MO, Zhou Y et al. Meta- and orthogonal integration of influenza 'OMICs' data defines a role for UBR4 in virus budding. Cell Host Microbe 2015; 18: 723-735.

57 Reimand J, Kull M, Peterson H, Hansen J, Vilo J. g:Profiler--a web-based toolset for functional profiling of gene lists from large-scale experiments. Nucleic Acids Res 2007; 35: W193-W200.

(Supplementary Information is linked to the online version of the paper on the Cell Discovery website.) 
(c) (i) This work is licensed under a Creative Commons Attribution 4.0 International License. The images or other third party material in this article are included in the article's Creative Commons license, unless indicated otherwise in the credit line; if the material is not included under the Creative
Commons license, users will need to obtain permission from the license holder to reproduce the material. To view a copy of this license, visit http://creativecommons.org/licenses/by/4.0/

(C) The Author(s) 2017 